Received: 2021/10/06, Revised: 2021/11/15, Accepted: 2021/12/05, Published: 2021/12/31 (๑2021 Masoud Khodaveisi et al.; Licence Physical Activity and Nutrition. This is an open access article distributed under the terms of the creative commons attribution license (https://creativecommons.org/licenses/by-nc/2.0/), which permits unrestricted use, distribution, and reproduction in any medium, provided the orginal work is properly cited.

*Corresponding author : Ali Jadidi

School of Nursing, Arak University of Medical Sciences, Arak, Iran

Tel: +989196657837

E-mail: jadidialili3@yahoo.com

(๑2021 The Korean Society for Exercise Nutrition

\section{Education based on the health belief model to improve the level of physical activity}

\author{
Masoud Khodaveisi ${ }^{1}$ / Bahman Azizpour ${ }^{1}$ / \\ Ali Jadidi ${ }^{\star}$ / Younes Mohammadi ${ }^{3}$
}

1. Chronic Disease (Home Care) Research Center, Hamadan University of Medical Sciences, Hamadan, Iran
2. School of Nursing, Arak University of Medical Sciences, Arak, Iran
3. Department of Epidemiology, Hamadan University of Medical Sciences, Hamadan, Iran

\section{INTRODUCTION}

Physical activity is any movement produced following skeletal muscle contraction, which increases energy consumption relative to the basal state $^{1}$. One criterion for a healthy community in 2020 is an increase in the percentage of moderate to intense regular physical activity to at least $50 \%$ and promoting physical activity. In addition, physical activity is a useful way to prevent chronic diseases and a cost-effective way to promote community health ${ }^{2}$.

Physical movement is one of the most important behaviors that can affect the occurrence of diseases. Physical inactivity increases the risk of breast and colon cancers, hypertension, lipid disorders, osteoporosis, depression, and anxiety ${ }^{3}$. Unhealthy eating, smoking, and physical inactivity are risk factors for chronic diseases. Removing these risk factors can prevent $2 \%-80 \%$ of heart diseases and type 2 diabetes and up to $40 \%$ of cancers. Exercise and physical activity have 60 different benefits ${ }^{4}$. Regular physical activity strengthens the immune system and can have positive psychological effects by reducing anxiety and depression and promoting confidence. Physical activity also has special economic benefits in terms of lowering the cost of medical care, increasing productivity, and improving the social environment ${ }^{5}$.

Despite the importance of adequate and regular physical activity, sedentary lifestyle is prevalent globally. According to worldwide statistics, $>60 \%$ of adults do not have the amount of physical activity necessary for health ${ }^{6}$. The prevalence of inactivity in the Iranian population aged 15-60 years was $58.8 \%$ in men, $76.3 \%$ in women, and $67.5 \%$ in both sexes. According to World Health Organization reports, $>2.3 \%$ of annual deaths are due to insufficient physical activity ${ }^{7}$.

Managers and employees are at high risk of inactivity and various diseases resulting from the uniformity of their work. Overweight and obesity are common and problematic side effects of desk jobs, and ignoring it will increase the susceptibility to various diseases. Therefore, educating people rightly and informing them are key to a healthy life ${ }^{8}$. Health education encourages and empowers people to adopt and practice 
voluntary health behaviors to promote and improve their health. Health education programs should be based on scientific models and theories so that the target group has more control over their health. One of the most important steps in educational planning is selecting a model based on the conditions and alignment of the model with the purpose of education $^{9}$. The health belief model (HBM) is one of the oldest and most practical models that explains and predicts health behaviors based on individual beliefs ${ }^{10}$. It is a comprehensive model that is more involved in disease prevention. According to this model, personal motivation to perform a health behavior relates to personal perceptions, modulating behaviors, and the likelihood of doing the behavior ${ }^{11}$. Since the efficacy of this model has not been evaluated by the staff, this study aimed to evaluate the effect of HBM-based education on the physical activity of the staff of Hamadan University of Medical Sciences.

\section{METHODS}

This semi-experimental study (pretest, posttest) was carried out on 130 teaching staff at Hamadan University of Medical Sciences from February 2018 to February 2019. The inclusion criteria of the study were as follows: (1) have at least 1 year of work experience, (2) lack of acute and chronic physical and mental illnesses, (3) aged 25-50 years, (4) not using drugs that affect physical activity, (5) have sufficient opportunity to participate in the educational course, and (6) no previous experience of training related to the subject of the present study during the past year. Those who were absent for more than one training session and those who were not satisfied with the study were excluded. People who missed more than one training session and those who did not consent to participate in the study were excluded. The samples were selected using a convenience sampling method from different faculties. Samples were divided into experimental and control groups using a block randomization method with a block size of 4 . Values of $\sigma_{1}^{2}=0.55$, $\sigma_{2}^{2}=0.6$, and d were extracted from the Rejali and Mostajeran study for sample size calculation. The minimum required number of samples in each group was calculated as 65 people by considering a $5 \%$ confidence interval, $90 \%$ test power, and $10 \%$ probability of sample loss.

$$
n=\frac{\left(Z_{1-\frac{\alpha}{2}}+Z_{1-\beta}\right)^{2}\left(\sigma_{1}^{2}+\sigma_{2}^{2}\right)}{\left(\mu_{2}-\mu_{1}\right)^{2}}
$$

Data were collected using a three-part tool: (1) demographic information questionnaire, (2) HBM Questionnaire, and (3) International Physical Activity Questionnaire (IPAQ). The demographic information questionnaire included questions about age, sex, marital status, education level, family income level, tobacco use, transportation to work, professional sports s location, height, weight, and body mass index. The HBM Questionnaire consisted of 47 questions with six major constructs: (1) perceived susceptibility (6 questions), (2) perceived severity (6 questions), (3) perceived benefits (11 questions), (4) perceived barriers (8 questions), (5) perceived self-efficacy (6 questions), and (6) cues to action (6 questions). The questions were answered on a five-choice Likert scale (ranging from very high to very low). In all questions (with the exception of perceived barriers), very high responses were given a score of 5, and a very low response was given a score of 1 . In perceived barriers questions, very high response was given a score of 1, and very low response was given a score of 5 .

The HBM Questionnaire was given to 10 science committee members of nursing and midwifery faculty with sufficient expertise and experience to assess the validity of the questionnaire (content validity index [CVI], content validity index [CVR]). After the validity assessment, questions with CVI and CVR less than the limit were corrected, modified, or removed. The reliability of the questionnaire in a pilot study of 10 university staff was calculated using Cronbach's alpha. Cronbach's alpha for the entire questionnaire was 0.767 . Cronbach's alpha values for the dimensions of perceived susceptibility, perceived severity, perceived benefits, perceived barriers, perceived self-efficacy, and practice guidelines were $0.810,0.752,0.742,0.779,0.704$, and 924, respectively.

The IPAQ measures an individual's overall physical activity over the past 7 days in terms of vigorous, moderate, walking, and sitting activities. The validity and reliability of the IPAQ have been assessed and confirmed in previous studies $^{12}$. For example, Tomioka et al.'s study showed that the CVR was 0.76 , and the CVI was 0.71 . The reliability of this questionnaire, which is measured by Cronbach's alpha, was $0.73^{13}$. In our study, only activities that were continuous for at least $10 \mathrm{~min}$ were considered. The total metabolic equivalent of task (MET) was used to measure the physical activity level. For this purpose, the minutes of daily vigorous, moderate, walking, and sitting activities were multiplied by the number of active days. Finally, the resulting value was multiplied by the MET level for each activity. MET levels for vigorous, moderate, walking, and sitting activities were $8,4,3.5$, and 0 , respectively. The total MET was calculated using the following formula:

$$
\begin{aligned}
& \text { Total MET } \frac{\text { minutes }}{\text { week }} \\
& =\text { Walk }(\text { METs } \times \min \times \text { days })+\operatorname{Mod}(\text { METs } \times \min \times \text { days }) \\
& +\operatorname{Vig}(\text { METs } \times \min \times \text { days })
\end{aligned}
$$

After providing the necessary explanations to the participants, the questionnaires were distributed among the experimental and control groups, and they were given enough time to respond to the questions. After the pretest phase, a training course based on the HBM was implemented for the experimental group. The experimental group was divided into six groups of 11 each, and three training sessions were held for each group. The training sessions were conducted 
by the first author (PhD in nursing). The duration of each training session was 90 min with a 10 -min interlude. The training session was held weekly. In the last training session, an educational booklet was provided to the intervention group. The booklet content was approved by several science committee members of the faculty of nursing and midwifery. Two months after the last training session, a posttest was performed by redistributing the questionnaires.

Data were analyzed using SPSS software (version 22). The mean and standard deviation were used for quantitative data description, and frequency and percentage were used for quantitative data description. Data analysis was performed using chi-square, paired t-test, Wilcoxon signed-rank test, independent $t$-test, Mann-Whitney U test, and simple linear regression. The Kolmogorov-Smirnov test was used to check the normality of the quantitative data distribution. The significance level was set at $\mathrm{P}<0.05$.

Prior to starting the study, all participants received written informed consent and were assured that all their information would remain confidential. People were given the option to withdraw at any stage of the study. The questionnaires were anonymous. The researcher pledged that the results of this research would not be reported individually. The control group was also given a prepared educational booklet at the end of the study. This study was approved by the research ethics committee of Hamadan University of Medical
Sciences (approval code: IR.UMSHA.REC.1396.815).

\section{RESULTS}

The subjects included 56 men (43.08\%) and 74 women $(56.92 \%)$ with a mean age of $39.93 \pm 8.74$ years. The results of statistical tests (Tables 1 and 2) showed no significant differences between the experimental and control groups in terms of demographic variables $(\mathrm{P}>0.05)$.

Perceived susceptibility, perceived severity, perceived benefits, perceived barriers, perceived self-efficacy, and cues to action were compared between the control and experimental groups before and after the educational intervention (Table 3 ). The results of the statistical tests revealed no significant difference between the two groups in terms of HBM constructs before training $(\mathrm{P}>0.05)$. However, after training, all HBM constructs in the intervention group were significantly greater than those in the control group ( $\mathrm{P}$ $<0.05)$. The HBM constructs in the control group did not change significantly after training $(\mathrm{P}>0.05)$. However, all HBM constructs in the intervention group were significantly increased compared to that before training $(\mathrm{P}<0.01)$.

Table 4 compares the physical activity of the staff between the experimental and control groups before and after training. Results of statistical tests showed no significant

Table 1. Comparison of qualitative demographic variables between the control and intervention groups.

\begin{tabular}{|c|c|c|c|c|}
\hline \multirow{2}{*}{\multicolumn{2}{|c|}{ Variables }} & \multicolumn{2}{|c|}{$\begin{array}{c}\text { Groups } \\
\text { Frequency }(\%)\end{array}$} & \multirow[t]{2}{*}{ Chi-squre test results } \\
\hline & & Control & Experimental & \\
\hline \multirow{2}{*}{ Sex } & Male & $27(41.5)$ & $29(44.6)$ & \multirow{2}{*}{$P=0.733$} \\
\hline & Female & $38(58.5)$ & $36(55.4)$ & \\
\hline \multirow{6}{*}{ Education level } & Under the diploma & $0(0 / 0)$ & $0(0.0)$ & \multirow{6}{*}{$P=0.715$} \\
\hline & Diploma & $16(24.6)$ & $18(27.7)$ & \\
\hline & Associate degree & $11(16.9)$ & $10(15.4)$ & \\
\hline & Undergraduate & $18(27.7)$ & $21(32.3)$ & \\
\hline & Master's degree & $20(30.8)$ & $15(23.1)$ & \\
\hline & Doctorate & $0(0.0)$ & $1(1.5)$ & \\
\hline \multirow{4}{*}{ Marital status } & Single & $12(18.5)$ & $10(15.4)$ & \multirow{4}{*}{$P=0.528$} \\
\hline & Married & $52(80.0)$ & $54(83.1)$ & \\
\hline & Divorced & $0(0.0)$ & $1(1.5)$ & \\
\hline & Deceased partner & $1(1.5)$ & $0(0 / 0)$ & \\
\hline \multirow{4}{*}{ Family income level } & $<10$ million rials & $0(0.0)$ & $1(1.5)$ & \multirow{4}{*}{$P=0.513$} \\
\hline & 10-20 million rials & $29(44.6)$ & $30(46.2)$ & \\
\hline & $>20$ million rials & $22(33.8)$ & $25(38.5)$ & \\
\hline & Unwillingness to respond & $14(21.5)$ & $9(13.8)$ & \\
\hline \multirow{4}{*}{ Tobacco using } & Cigarette & $3(4.6)$ & $1(1.5)$ & \multirow{4}{*}{$P=0.093$} \\
\hline & Hookah & $4(6.2)$ & $0(0 / 0)$ & \\
\hline & Others & $1(1.5)$ & $0(0 / 0)$ & \\
\hline & None & $57(87.7)$ & $64(98.5)$ & \\
\hline \multirow{3}{*}{ Transportation to work } & Private vehicles & $40(61.5)$ & $38(58.5)$ & \multirow{3}{*}{$P=0.823$} \\
\hline & Public transportation & $14(21.5)$ & $17(26.2)$ & \\
\hline & None & $11(16.9)$ & $10(15.4)$ & \\
\hline \multirow{2}{*}{ Professional sports history } & Yes & $31(47.7)$ & $24(36.9)$ & \multirow{2}{*}{$P=0.287$} \\
\hline & No & $34(52.3)$ & $41(63.1)$ & \\
\hline \multirow{3}{*}{ Living location } & City & $51(78.5)$ & $53(81.5)$ & \multirow{3}{*}{$P=0.716$} \\
\hline & Village & $2(3.1)$ & $3(4.6)$ & \\
\hline & The surrounding settlements & $12(18.5)$ & $9(13.8)$ & \\
\hline
\end{tabular}


Table 2. Comparison of quantitative demographic variables between the control and intervention groups.

\begin{tabular}{|c|c|c|c|}
\hline \multirow[t]{2}{*}{ Variables } & \multicolumn{2}{|c|}{$\begin{array}{c}\text { Groups } \\
\text { Mean } \pm \text { standard deviation }\end{array}$} & \multirow[t]{2}{*}{ Statistical test results } \\
\hline & Control & Experimental & \\
\hline Age (year) & $40.72 \pm 9.36$ & $39.14 \pm 8.06$ & $\begin{array}{l}\text { Mann-Whitney U } \\
\quad P=0.303\end{array}$ \\
\hline Height (cm) & $169.98 \pm 7.14$ & $168.35 \pm 7.56$ & $\begin{array}{c}\text { Mann-Whitney U } \\
\mathrm{P}=0.231\end{array}$ \\
\hline Weight (kg) & $74.03 \pm 11.12$ & $70.92 \pm 74.03$ & $\begin{array}{l}\text { Independent samples T } \\
\qquad P=0.101\end{array}$ \\
\hline BMI $\left(\mathrm{kg} / \mathrm{m}^{2}\right)$ & $25.61 \pm 3.52$ & $24.97 \pm 3.02$ & $\begin{array}{l}\text { Independent samples T } \\
\qquad P=0.303\end{array}$ \\
\hline
\end{tabular}

Table 3. Comparison of dimensions of the health belief model between the control and intervention groups before and after training.

\begin{tabular}{|c|c|c|c|}
\hline Groups & Before training & After training & Statistical test results \\
\hline \multicolumn{4}{|c|}{$\begin{array}{l}\text { Perceived susceptibility } \\
\text { Mean } \pm \text { standard deviation }\end{array}$} \\
\hline Control & $17.78 \pm 5.10$ & $18.33 \pm 4.72$ & ${ }^{++} P=0.645$ \\
\hline Experimental & $17.43 \pm 4.59$ & $22.43 \pm 3.53$ & ${ }^{++} P<0.001$ \\
\hline Statistical test results & $* \mathrm{P}=0.772$ & $*{ }^{*} \mathrm{P}<0.001$ & \\
\hline \multicolumn{4}{|c|}{$\begin{array}{c}\text { Perceived severity } \\
\text { Mean } \pm \text { standard deviation }\end{array}$} \\
\hline Control & $19.47 \pm 5.22$ & $19.93 \pm 5.07$ & ${ }^{++} P=0.620$ \\
\hline Experimental & $19.87 \pm 4.91$ & $22.26 \pm 4.33$ & ${ }^{++} P=0.008$ \\
\hline Statistical test results & ${ }^{*} \mathrm{P}=0.654$ & $\mathrm{P}=0.007$ & \\
\hline \multicolumn{4}{|c|}{$\begin{array}{c}\text { Perceived benefits } \\
\text { Mean } \pm \text { standard deviation }\end{array}$} \\
\hline Control & $42.44 \pm 8.02$ & $41.87 \pm 7.73$ & ${ }^{++} P=0.472$ \\
\hline Experimental & $43.92 \pm 8.93$ & $48.64 \pm 5.27$ & ${ }^{++} P<0.001$ \\
\hline Statistical test results & ${ }^{*} \mathrm{P}=0.083$ & ${ }^{*} \mathrm{P}<0.001$ & \\
\hline \multicolumn{3}{|c|}{ Perceived barriers } & Mean \pm standard deviation \\
\hline Control & $29.49 \pm 7.15$ & $29.09 \pm 5.99$ & ${ }^{+} P=0.732$ \\
\hline Experimental & $27.66 \pm 6.02$ & $31.64 \pm 7.00$ & ${ }^{+} P=0.002$ \\
\hline Statistical test results & $* P=0.117$ & ${ }^{*} \mathrm{P}=0.027$ & \\
\hline \multicolumn{4}{|c|}{$\begin{array}{c}\text { Perceived self-efficacy } \\
\text { Mean } \pm \text { standard deviation }\end{array}$} \\
\hline Control & $28.64 \pm 9.37$ & $29.01 \pm 8.20$ & ${ }^{++} P=0.935$ \\
\hline Experimental & $36.26 \pm 7.12$ & $28.29 \pm 6.65$ & ${ }^{++} P<0.001$ \\
\hline Statistical test results & ${ }^{*} \mathrm{P}=0.685$ & ${ }^{*} \mathrm{P}<0.001$ & \\
\hline \multicolumn{2}{|c|}{ Mean \pm standard deviation } & & \\
\hline Control & $17.67 \pm 4.43$ & $19.04 \pm 4.95$ & ${ }^{++} P=0.080$ \\
\hline Experimental & $18.13 \pm 4.96$ & $21.49 \pm 3.65$ & ${ }^{++} P<0.001$ \\
\hline Statistical test results & $* P=0.299$ & $\mathrm{P}<0.000$ & \\
\hline
\end{tabular}

+ Paired samples $t$-test, ${ }^{++}$Wilcoxon signed-rank test, $\bullet$ independent samples $t$-test, ${ }^{\bullet \bullet}$ Mann-Whitney U-test.

Table 4. Comparison of physical activity between the control and intervention groups before and after training.

\begin{tabular}{cccc} 
Groups & \multicolumn{2}{c}{$\begin{array}{c}\text { Physical activity } \\
\text { Mean } \pm \text { standard deviation }\end{array}$} & After training \\
Control & Before training & $3,625.69 \pm 3,941.87$ & Statistical test results \\
Experimental & $3,648.30 \pm 4,760.72$ & $3,943.15 \pm 5,567.34$ & $\mathbf{P}=\mathbf{0 . 9 7 7}$ \\
Statistical test results & $2,679.47 \pm 2,995.59$ & $\mathbf{P = 0 . 2 9 7}$ & $\mathbf{P}=\mathbf{0 3 3 3}$ \\
\hline
\end{tabular}


Table 5. Prediction of physical activity using health belief model constructs.

\begin{tabular}{|c|c|c|c|c|c|}
\hline \multirow{2}{*}{ Independent variables } & \multicolumn{2}{|c|}{ Unstandardized coefficients } & \multirow{2}{*}{$\begin{array}{c}\text { Standardized coefficients } \\
\text { Beta }\end{array}$} & \multirow{2}{*}{$\mathbf{t}$} & \multirow{2}{*}{ P-value } \\
\hline & B & Standard error & & & \\
\hline Constant & -805.37 & $3,249.56$ & - & -0.24 & 0.805 \\
\hline Perceived Susceptibility & -0.55 & 104.74 & -0.54 & -0.53 & 0.594 \\
\hline Perceived severity & 119.80 & 90.96 & 0.12 & 1.31 & 0.190 \\
\hline Perceived benefits & -53.15 & 70.95 & -0.08 & -0.74 & 0.455 \\
\hline Perceived barriers & -119.21 & 67.96 & 0.16 & 1.75 & 0.082 \\
\hline Perceived self-efficacy & -170.37 & 68.13 & 0.30 & 2.50 & 0.014 \\
\hline Cues to action & -182.38 & 115.25 & -0.17 & -1.58 & 0.116 \\
\hline
\end{tabular}

difference between the two groups in terms of physical activity before and after the training intervention $(\mathrm{P}>0.05)$. Moreover, physical activity of the control and experimental groups did not change significantly after training $(\mathrm{P}>0.05)$.

In Table 5, physical activity is predicted through linear regression based on its relationship with other HBM major components, with $\mathrm{P}<0.05(\mathrm{P}=0.049)$ and $\mathrm{R}^{2}=0.310$, indicating that this model is a good predictor of physical activity. According to this model, only the self-efficacy variable is a good predictor of physical activity $(\mathrm{P}<0.05)$.

\section{DISCUSSION}

In this study, the effect of HBM-based education on the physical activity of university staff was evaluated. The two groups were matched for all demographic variables. Therefore, the observed differences in outcome variables can be attributed to the direct effect of education. The findings of this study showed an increase in the level of perceived susceptibility in the experimental group, unlike that in the control group, after the training course. The improvement of perceived susceptibility in the experimental group means that the experimental group felt more at risk of disease than that in the control group after training. This can be attributed to increased staff information on susceptibility to diseases. However, our study did not measure the awareness level of staff before and after the educational intervention, which is consistent with the findings of Malak et al. ${ }^{14}$, Abood et al. ${ }^{15}$, and Amodeo et al. ${ }^{16}$. According to a study by Mulualem et al., higher perceived susceptibility is associated with a higher likelihood of preventive behavior ${ }^{17}$.

In the present study, training significantly increased the mean scores of perceived severity in the experimental group, but the perceived severity scores of the control group did not change significantly. These findings indicate that the experimental group had a greater understanding of the inactivity consequences than that in the control group. This finding is in line with those of other studies ${ }^{18-21}$. People's risk assessment is the central axis of the HBM, so perceived severity should be considered a weak shaper of behavior ${ }^{23}$. Based on Orji et al.'s study, individual perception of disease severity and its consequences and complications is one of the key components of an HBM that is effective in adopting preventive behaviors $^{23}$.

In the present study, perceived benefits and barriers scores showed a significant increase in the experimental group after training, whereas in the control group, it did not change significantly. The study results of Romano et al. and Orji et al. ${ }^{21,23}$ are consistent with the findings of the present study. The increased perceived benefits score in our study can be attributed to the strong emphasis on physical activity, its physical and psychological benefits, and the role of exercise in disease prevention in part of the educational course. In other words, individual perceptions of benefits pave the way for action ${ }^{24}$. Abood et al. showed that the HBM effectively increased the perceived benefits score in the experimental group, but failed to reduce the perceived barriers score, possibly due to reduced follow-up and people returning to their previous lifestyle ${ }^{15}$. Mardani Hamuleh et al., in their study, stated that perceived barriers are the most important component of the HBM, and behavior is less likely to occur if perceived barriers prevail over perceived benefits ${ }^{25}$.

The findings of our study showed a significant increase in self-efficacy in the experimental group after training, but this change was not observed in the control group. Additionally, self-efficacy was identified as the most important predictor of physical activity in our study. In Moschny et al., self-efficacy served as a predictor of physical activity behavior in older adults ${ }^{26}$. In addition, Abood et al. and Shin et al. considered self-efficacy as an important factor in physical activity ${ }^{15,27}$. It seems that people's belief that they are able to correctly perform health behaviors can be effective in promoting self-efficacy in the community. People's confidence in their ability to perform health behaviors results in that behavior. Our results are consistent with Hakanen and Roodts study ${ }^{28}$.

In our study, the mean score of cues to action in the experimental group increased significantly after training compared to that pre-training, whereas no significant change was observed in the control group. This finding is in line with the results of Gristwood et al. and Kim et al. ${ }^{20,29}$. It is noteworthy that the mean score of cues to action in the 
control group also increased. Although this change was not significant, it was slightly different from the significant level $(\mathrm{P}=0.08)$. It seems that some members of the control group have been able to upgrade their practice score through the media and other sources during this time.

In the present study, training improved the physical activity performance of the experimental group. However, this increase was not significant, which may be due to the high dispersion of data. The level of physical activity in the control group slightly decreased. However, in this study, a self-report method was used to measure the physical activity of staff, which seems to be associated with some errors. This finding was observed in similar studies, such as those by James et al. ${ }^{7}$ and Min and $\mathrm{Oh}^{11}$. Therefore, the level of physical activity of individuals can be improved by providing them with the necessary training.

The limitations of this study include a short follow-up time, difficulty in measuring physical activity due to the use of self-report methods, and lack of evaluation of participants' awareness.

The training-based HBM model led to an improvement in the scores of perceived susceptibility, perceived severity, perceived benefits, perceived barriers, perceived self-efficacy, cues to action, and physical activity levels among the staff of Hamadan University of Medical Sciences. Self-efficacy constructs were also identified as strong predictors of physical activity. It is suggested that long-term follow-up should be performed in future studies. In addition, a method is used to measure the physical activity levels with more reliability. It is also recommended to use more sample volumes in future studies. Comparative studies are also recommended to compare the efficacy of the HBM with other models in increasing physical activity.

\section{ACKNOWLEDGEMENTS}

This study was extracted from a research project at Hamadan University of Medical Sciences. The authors thank the Vice-Chancellor for Research and Technology of Hamadan University of Medical Sciences for the financial and administrative support. This study was supported by Hamadan University of Medical Sciences. The study was conducted after receiving an ethics code (no. IR.UMSHA. REC.1396.815) by the Research Ethics Committee of Hamadan University of Medical Sciences. Additionally, the participants were ensured of information confidentiality, and written consent was obtained for their participation in the study.

\section{REFERENCES}

1. Moodi M, Sharifzadeh G, Rakhshany Zabol F. Effectiveness of an educational program based on the transtheoretical model to increase use of the processes of change for physical activity among the employees of birjand universities. J Community Health Res. 2017:3:9-19.
2. Rejali M, Mostajeran M. Assessment of physical activity in medical and public health students. J Educ Health Promot. 2013;2:9-12.

3. Chen S, Gu X. Effects of cardiorespiratory fitness and weight status on knowledge of physical activity and fitness, attitude toward physical education, and physical activity. BMC Public Health. 2018;18:273.

4. Song MR, Lee YS, Baek JD, Miller M. Physical activity status in adults with depression in the national health and nutrition examination survey, 2005-2006. Public Health Nurs. 2012;29:208-17.

5. Taymoori P, Niknami S, Berry T, Ghofranipour F, Kazemnejad A. Application of the health promotion model to predict stages of exercise behaviour in Iranian adolescents. East Mediterr Health $\mathrm{J}$. 2009;15:1215-25.

6. Sedghi F, Lael-monfared E. Effect of intervention counseling 5a step method based on the structure on stage of change to promote physical activity female employees in mashhad factories industrial. Public Health Res Pract. 2016;14:59-70.

7. James DC, Pobee JW, Brown L, Joshi G. Using the health belief model to develop culturally appropriate weight-management materials for African-American women. J Acad Nutr Diet. 2012;112:66470.

8. Pahor M, Guralnik JM, Ambrosius WT, Blair S, Bonds DE, Church TS, Espeland MA, Fielding RA, Gill TM, Groessl EJ, King AC, Kritchevsky SB, Manini TM, McDermott MM, Miller ME, Newman AB, Releski WJ, Sink KM, Williamson JD. Effect of structured physical activity on prevention of major mobility disability in older adults: the LIFE study randomized clinical trial. Jama. 2014;311:2387-96.

9. Glanz K, Rimer BK, Viswanath K. Health behavior and health education: theory, research, and practice. John Wiley \& Sons; 2008.

10. Goodpaster BH, DeLany JP, Otto AD, Kuller L, Vockley J, SouthPaul JE, Thomas SB, Brown J, McTique K, Hames KC, Lang W, Jakicic JM. Effects of diet and physical activity interventions on weight loss and cardiometabolic risk factors in severely obese adults: a randomized trial. Jama. 2010;304:1795-802.

11. Min H, Oh HY. A study on osteoporosis knowledge, health beliefs and health behaviors among female college students. J Korean Acad Community Health Nurs. 2011;22:111-20.

12. Craig $C L$, Marshall $A L$, Sjöström $M$, Bauman $A E$, Booth $M L$, Ainsworth BE, Pratt M, Ekelund U, Yngve A, Sallis JF, Oja P. International physical activity questionnaire: 12-country reliability and validity. Med Sci Sports Exerc. 2003;35:1381-95.

13. Gillard S, Shamley D. Factors motivating women to commence and adhere to pelvic floor muscle exercises following a perineal tear at delivery: the influence of experience. J Assoc Chart Physiother Women's Health. 2010;106:5-18.

14. Malak MZ, Toama ZT. The effect of osteoporosis health education program based on health belief model on knowledge and health beliefs towards osteoporosis among Jordanian female teachers. Eur Sci J. 2015;1:385-98.

15. Abood DA, Black DR, Feral D. Nutrition education worksite intervention for university staff: application of the health belief model. $J$ Nutr Educ Behav. 2003;35:260-7.

16. Amodeo R, De AP, Sorbara L, Avanzini F, Di Giulio P, De Martini $M$. How to increase patient knowledge of their coronary heart disease: impact of an educational meeting led by nurses. $G$ Ital. 2009;10:249-55.

17. Mulualem D, Henry CJ, Berhanu G, Whiting SJ. The effective- 
ness of nutrition education: applying the Health Belief Model in child-feeding practices to use pulses for complementary feeding in Southern Ethiopia. Ecol Food Nutr. 2016;55:308-23.

18. Alseraty WHH, Ali WGM. The impacts of health belief model based intervention for osteoporosis prevention among female students in Aldawadmi applied medical science, Shaqraa university, Saudi Arabia. J Biol Agric Healthc. 2014;4:125-31.

19. Dhimal M, Aryal KK, Dhimal ML, Gautam I, Singh SP, Bhusal CL, Kuch U. Knowledge, attitude and practice regarding dengue fever among the healthy population of highland and lowland communities in central Nepal. PLoS One. 2014;9:e102028.

20. Gristwood J. Applying the health belief model to physical activity engagement among older adults. Illuminare. 2011;9:59-71.

21. Romano V, Scott I. Using health belief model to reduce obesity amongst African American and Hispanic populations. Procedia Soc Behav Sci. 2014;159:707-11.

22. Ayele K, Tesfa B, Abebe L, Tilahun T, Girma E. Self care behavior among patients with diabetes in Harari, Eastern Ethiopia: the health belief model perspective. PloS one. 2012;7:e35515.

23. Orji R, Vassileva J, Mandryk R. Towards an effective health interventions design: an extension of the health belief model. Online $J$ Public Health Inform. 2012;4:1-31.

24. Tayel AA, El Sherbini HH, Abou Shosha AAEF, Abdou RA. The effect of applying preventive intervention based on champion health believe model on breast cancer fatalism, knowledge and screening behaviors among female employees. Am J Nurs Res. 2019;7:75970.

25. Mardani Hamuleh M, Shahraki Vahed A, Piri AR. Effects of education based on health belief model on dietary adherence in diabetic patients. J Diabetes Metab Disord. 2010;9:1-6.

26. Moschny A, Platen P, Klaaßen-Mielke R, Trampisch U, Hinrichs T. Barriers to physical activity in older adults in Germany: a cross-sectional study. Int J Behav Nutr Phys Act. 2011;8:121.

27. Shin YH, Hur HK, Pender NJ, Jang HJ, Kim M-S. Exercise self-efficacy, exercise benefits and barriers, and commitment to a plan for exercise among Korean women with osteoporosis and osteoarthritis. Int J Nurs Stud. 2006;43:3-10.

28. Hakanen JJ, Roodt G. Using the job demands-resources model to predict engagement: analysing a conceptual model. Work engagement: a handbook of essential theory and research. 2010:85-101.

29. Kim HS, Ahn J, No JK. Applying the health belief model to college students' health behavior. Nutr Res Pract. 2012;6:551-8. 